\title{
Traducción comentada de "Da Verga a Sciascia: la sfida dei siciliani", conferencia de Antonio Di Grado
}

\author{
Sabina LonghitANO PIAZZA \\ Facultad de Filosofía y Letras \\ Universidad Nacional AutónOMA de MÉXICO \\ México
}

\section{Introducción}

Presento aquí la traducción comentada de la conferencia "Da Verga a Sciascia: la sfida dei siciliani", dictada por el Prof. Antonio Di Grado el 5 de noviembre de 2019 en el Instituto Italiano de Cultura de la Ciudad de México. Se trata de una valoración de amplio respiro de la literatura y cultura siciliana en el contexto postunitario y en la primera mitad del siglo XX.

En una visión que los intelectuales sicilianos comparten con el pueblo de la isla, tanto Sicilia como todo el Sur de Italia fueron anexados al Reino de Italia con un proceso doloroso, a partir de la expedición de Garibaldi y sus mil voluntarios ( $i$ Mille), cuyo éxito fue determinado por las rebeliones de los más pobres, los campesinos, sujetos a un sistema poco menos que feudal, quienes de la anexión se esperaban la reforma agraria y la impartición de una justicia efectiva y no sesgada (cuando no cegada) por el censo. El nuevo Estado italiano, además de reprimir duramente los excesos de las revueltas campesinas, promulgó leyes (como el servicio militar obligatorio) e instituyó impuestos (como el gravamen sobre la molienda del trigo) que afectaban gravemente a la población rural, quienes eran los más pobres. Sus funcionarios, en muchos casos corruptos y rapaces, consideraban al Sur de Italia como una colonia. La guerrilla que los pobres emprendieron en contra del Estado, conocida como brigantaggio, fue ferozmente reprimida, con un saldo de miles de muertos en pocos años. En los años noventa del siglo XIX un nuevo movimiento de reivindicación social, el de los Fasci siciliani, luchó por la abolición de los impuestos directos y por la redistribución de la tierra: después de tres años de huelgas, de una fuerte lucha social y de que en toda la Isla fuera declarado el estado de emergencia, el movimiento fue reprimido en 1893. A cada oleada de represión correspondía una, aún mayor, de emigración: pocos saben que también Italia tuvo su tragedia naval, como la del Titanic: el 4 de agosto de 1906 el Sirio, 
con 80 pasajeros de primera clase, 40 de segunda y casi 1,200 en tercera clase, se hunde frente a Génova, con un saldo de entre 300 y 500 muertos.

Es en este contexto que se desarrolla la literatura verista de Giovanni Verga y Luigi Capuana, que representa la base de la novela italiana del siglo Xx, introduciendo "en el salón" de la literatura italiana a los pobres, los oprimidos, los vencidos; son éstas las premisas para que la literatura siciliana post-unitaria se conforme como una visión de los vencidos, como un juicio a la Historia, como una crítica a una falsa y mendaz idea de progreso, a las mentiras del Poder, a la hipocresía del gatopardismo: tal y como los nobles sicilianos, después de la victoria de Garibaldi, se pasan inmediatamente al bando del nuevo Rey, así los jerarcas fascistas, al día después de la llagada de los Aliados, en 1943, se reciclarán en el poder como sinceros democráticos. Y es una verdadera genealogía la de los escritores sicilianos que, desde finales del siglo XIX hasta la mitad del XX, se abocan a una representación escéptica, crítica y desmitificadora de la Historia y de su impacto en las pequeñas historias de la gente común.

Proponer este texto aquí, en el contexto latinoamericano actual, representa una contribución a los debates y estudios sobre producciones literarias periféricas, liminales, con una perspectiva explícita o implícitamente poscolonial. En oposición a una retórica "sicilianista" y provinciana, a una visión hipócritamente romántica de la miseria y del subdesarrollo, al costumbrismo folklórico y a la resignación gatopardesca, al inmovilismo y la corrupción en la Isla, los intelectuales sicilianos se colocan en un marco cultural cosmopolita, europeo, haciendo de una "tradición científica de alto nivel, y de una vocación intelectual consecuentemente escéptica, laica, materialista", un afilado instrumento para leer con pasión y lucidez la realidad der su isla. Di Grado retoma la afirmación de Sciascia que no hubo escritores románticos en Sicilia: desde la perspectiva de los conquistados, los vencidos, los colonizados, no puede haber ilusiones en un progreso que se percibe como falso; por esta misma razón los intelectuales sicilianos desconfían en el idealismo con tintes nacionalistas y fascistas de los comienzos del Xx. Su mayor exponente, Giovanni Gentile, paradójicamente él también siciliano, profetizó el ocaso de la cultura siciliana, que él justamente consideraba la última cultura regional italiana, con "su tradición materialista y realista y su orgullosa alteridad, su prejuicio crítico sobre la magnífica suerte de la Nación proclamada por el Poder, su vocación a la duda y al disentimiento", porque irreducible a una cultura italiana a hegemonía idealista.

Aquí se ofrece una traducción no sólo del texto sino también de todos los fragmentos literarios que se citan. Los títulos de las obras los dejé en italiano, ya que no siempre están traducidos: de ser el caso, en la Bibliografía se encuentra la referencia a la traducción más reciente al español o, de no ser el caso, a algún otro idioma europeo. Con respecto al texto original, de los autores mencionados en el artículo agregué, al menos la primera vez, el nombre de pila, para facilitar su búsqueda posterior. 
Finalmente, traté de conservar lo más posible los rasgos estilísticos del texto, que es un excelente ejemplo de ensayo literario de estilo italiano contemporáneo, por su densidad tanto conceptual como sintáctica y léxica, con una fuerte presencia de alusiones y citas indirectas (que el autor señala sólo por medio de comillas) que decidí mantener en italiano cuando aluden a textos en italiano, traduciéndolas y reconstruyendo la alusión en nota.

\title{
De Verga a Sciascia: el reto de los sicilianos
}

\author{
Antonio Di GRADO \\ Università di Catania ${ }^{1}$
}

El protagonista de una novela de Víctor Hugo, un deforme bufón que había descubierto ser un Lord de Inglaterra, gritaba en la Cámara de los Lores, a aquellos señores ociosos y rapaces: "Milores, vengo a darles una noticia. El género humano existe".

El género humano existe. Esto es lo que anuncian los grandes escritores sicilianos, comenzando por Giovanni Verga, que hace irrumpir a los "vencidos" con sus necesidades y sus heridas en el salón de la literatura, y Federico De Roberto, quien desvela las mentiras de los poderosos revelando cómo cambian de bando con tal de mantener el poder, prosiguiendo con Salvatore Quasimodo y Elio Vittorini, quienes cantan "el mundo ofendido" y "el género humano de los muertos de hambre", Vitaliano Brancati, quien a las dictaduras les opone el sentido común de los hombres cualquiera, para llegar a Leonardo Sciascia, quien denuncia las derrotas de la Razón y las mentiras del Poder.

Es un juicio a la Historia: a la hecha y escrita por los vencedores. En I Vicerè de De Roberto (1894), en Pirandello y Brancati, en Tomasi di Lampedusa y Sciascia, se elabora y se perfecciona la crítica de un falso progreso, de los cambios aparentes, de las mistificaciones por medio de las cuales se perpetúa la dominación.

Tomo las páginas que cito para comenzar de un cuento largo, "L'antimonio" de Leonardo Sciascia (1960), precisamente del joven Sciascia quien estaba aprendiendo el oficio en el taller de Elio Vittorini, su lección de compromiso civil y de fe en la literatura, en la palabra, que es memoria y advertencia y se puede transformar en acción y cambio. En ellas se narra de un humilde zolfataro siciliano, un

\footnotetext{
${ }^{1}$ Traducción, edición y notas de la Traductora, de la conferencia "Da Verga a Sciascia: la sfida dei siciliani”, dictada por el Prof. Dr. Antonio Di Grado el 5 de noviembre de 2019 en el Instituto Italiano de Cultura, Ciudad de México. Una versión anterior de este texto ha sido publicada en italiano con el título "Memoria e utopia: la vocazione europea della letteratura siciliana" (Di Grado: 2009).
} 
trabajador de las minas de azufre, reclutado, por ignorancia y por hambre, en la guerra fascista en contra de la república y del pueblo de España: de aquella guerra, y de la España de García Lorca y de la Pasionaria, un mito que despertó las consciencias de más de una generación, de Vittorini a Sciascia, aquel minero-soldado había vuelto mutilado. Y así se expresaba:

La guerra me había marcado de condena en el cuerpo. Pero cuando un hombre ha entendido que es una imagen de dignidad, ustedes pueden llegar a tratarlo como un tronco, desgarrarlo por todas partes, y siempre será la cosa más grande de Dios. Cuando las tropas nuevas llegan a un frente y son lanzadas a la batalla, generales y periodistas dicen: "tuvieron su bautismo del fuego", una de las muchas frases solemnes y estúpidas con las que se acostumbra cubrir la bestialidad de las guerras: pero de la guerra de España, del fuego de aquella guerra, pienso haber recibido de verdad un bautismo: un signo de liberación en el corazón; de conocimiento; de justicia [...]. Lo que más me hería y me hacía más solo era la indiferencia de todos a las cosas tremendas que yo había vivido y que España aún vivía [...]. Quizá todos los veteranos suelen quemarse frente a la indiferencia de los demás y encerrarse en sí mismos, hasta que la vida de todos los días, el trabajo la familia los amigos, los vuelve a absorber y asimilar: pero cuando uno vuelve de una guerra como la de España, con la certidumbre de que su casa se va a quemar con el mismo fuego, no logra transformar su experiencia en recuerdo y retomar el sueño de los hábitos cotidianos; al contrario, quiere que también los demás estén despiertos, que también los demás sepan.

Pero los demás querían dormir. Talmente pobre, y, en la pobreza, cobarde era mi pueblo, que con envidia todos me decían "Te hiciste de un buen dinero, ahora puedes vivir tranquilo" hasta los ricos me lo decían. Si no hubiera perdido una mano habría vuelto a la mina de azufre; era España también la mina de azufre, el hombre explotado como bestia y el fuego de la muerte al acecho siempre a punto de desbordarse de un resquicio, el hombre con su blasfemia y su odio, la esperanza frágil como los blancos brotes de trigo del viernes santo en la blasfemia y el odio. (Sciascia, 2012: $242-248)^{2}$

Nosotros tampoco queremos saber. Nosotros también olvidamos. A quienes hoy pretenden nulificar la historia, domesticar y aplanar aquella historia, borrar las diferencias y reconciliar fascismo y antifascismo, opresores y oprimidos, la literatura de los Sicilianos se contrapone ofreciéndose como un teatro de la memoria y como una trinchera, un puesto de vigilancia desde el cual dar el alarma sobre toda suerte de mistificación, de homologación, de olvido culpable. Por ende, a los escritores de Sicilia podría adaptarse la definición de "militantes de la memoria", de

${ }^{2}$ La traducción de los fragmentos literarios citados en el texto es a cargo de la traductora del artículo. Los títulos de las obras los dejé en italiano, ya que no siempre están traducidos: de ser éste el caso, la referencia bibliográfica a la traducción más reciente al español o, de no ser el caso, a algún otro idioma europeo, se encuentra en la Bibliografía. Como se trata de un texto que también hace uso de alusiones y citas indirectas (que el autor señala sólo por medio de comillas), las mantuve en italiano — por ser icónicas en muchos casos - traduciéndolas o reconstruyendo la alusión en nota. 
la cual se engalanaron los anónimos miembros de aquella sociedad de los "justos" que, en el siglo pasado, se habían tomado la tarea de salvar al menos una vida de los lager nazi o, aun antes, del exterminio turco de los armenios.

Pero no es sólo para decir esto que empecé con esta página. El minero del "Antimonio", y el joven Sciascia, que en el corazón soleado y desolado de la isla plasma su educación antifascista $-\mathrm{y}$ su culto a la literatura-, atestiguan una oposición a la retórica provinciana y sicilianista de quienes representan la literatura siciliana arraigada, como las ostras de Verga, al escollo-Sicilia y a los legados del subdesarrollo, a las coloridas y risueñas coreografías folklóricas, al escepticismo de los Gatopardos, a la malicia, la corrupción y al inmovilismo de los gobiernos de la isla.

La de los grandes intelectuales sicilianos de la edad moderna es, al contrario, una vocación decididamente transnacional y cosmopolita: para demostrarlo, no es necesario remontar a las cumbres - y a la política cultura - de la corte del emperador Federico II ni fantasear sobre el encuentro, en las cárceles argelinas, entre Miguel de Cervantes y el poeta siciliano Antonio Veneziano (sin embargo no es fácil sustraerse a la fascinación de esa conjetura, tenue pero fecunda, pues alude a las relaciones inexploradas de la cultura isleña con los fantasmas de la hispanidad, con las multiformes expresiones de la morada mediterránea).

Será suficiente comenzar, más bien, por el Settecento del palermitano Giovanni Meli y de Domenico Tempio, de Catania, cuando este último tomaba las ideas y los excesos de su poema, La Caristia (Tempio, 1848), magmática y truculenta escenificación de las plagas de la miseria y de la revolución popular, no sólo de los humores y del dialecto del subproletariado urbano, sino también de los libros prohibidos de los Ilustrados franceses, febril - y clandestinamente - consultados en la biblioteca del obispo por él y un puñado de jóvenes intelectuales quienes en la revolución del '89 habían visto la encarnación —así escribía uno de ellos, Giovanni Gambino - del reino de Dios en la tierra, y después pagaron con el exilio, como el mismo Gambino, conjurado y fugitivo, luego funcionario napoleónico en Milán y finalmente, después de una ulterior decepción, pastor calvinista en Ginevra; o, como Tempio, conjugaron en sus versos desencanto y disimulación, rabia y desesperada poesía.

En la pauta de una tradición científica de alto nivel, y de una vocación intelectual consecuentemente escéptica, laica, materialista, una continuidad sin rupturas conecta, cien años después, la estación de la Ilustración con la del verismo de Giovanni Verga, Luigi Capuana, Federico De Roberto. Sicilia ignoró el Romanticismo, lo saltó de pies juntitos, al no poder — valiéndose de aquella tradición - confiar en la ilusión de las "magnifiche sorti e progressive"; de la

\footnotetext{
${ }^{3}$ Se trata del celebérrimo v. 51 del poema "La ginestra" de Giacomo Leopardi (1835): "Son palabras de Terenzio Mamiani, que Leopardi [...] retoma irónicamente; Mamiani, en la 'Dedicatoria' de 1832 a sus Himnos Sacros, a partir de la tesis según la cual 'la vida civil comienza en la religión', hablaba de la ley
} 
misma manera, y valiéndose del mismo rigor, desconfiará en la reacción idealista y espiritualista del primer Novecientos. Y una vez más es a la literatura transalpina, a Flaubert, Zola, Maupassant y a la cultura positivista europea, de la que se abrevan nuestros escritores veristas para refundar la literatura y la novela en Italia, para que en ellas irrumpan los barrios bajos de la sociedad, las violencias de la historia.

De aquella historia entretejida de violencias y de engaños, y de la suerte inmudable de las clases dirigentes isleñas, será el De Roberto de I Vicerè quien emitirá el despiadado diagnóstico, y estrenará una lectura de la historia como perpetuo transformismo, como invalidación del cambio por parte de oligarquías arraigadas en el poder y decididas, para mantenerlo, a saltar al carro del vencedor y mudar de bandera y de ideología con soltura. Una lectura ya implícita en el mismo Tempio de La Caristia donde la revolución estalla y se extingue con la efímera virulencia de un carnaval, y en el Verga del cuento "Libertà" (Verga, 1883), donde lo que alimenta la revolución son las expectativas de igualdad social surgidas con la llegada de Garibaldi con su ejército de voluntarios, quienes sin embargo la reprimirán, desmintiendo esas ilusiones. Y así seguirá desde la unificación de Italia, manejada por las mismas élites que habían convenido con el viejo régimen borbónico - como en los ya mencionados Vicerè de De Roberto y, más adelante, a pesar de sus perspectivas distintas, Il Gattopardo de Tomasi di Lampedusa (1958) e "Il Quarantotto" de Sciascia (1958) —, hasta los años siguientes, los de la Sinistra de Crispi y de Giolitti y del transformismo imperante, que definitivamente arrasa con las ilusiones del Risorgimento, como en L'Imperio de De Roberto (1929) e I vecchi e i giovani de Pirandello (1913).

Y seguirá aun así con el viraje de la liberación del fascismo, una vez más hecho vano, cuando (por ejemplo en el cuento de Brancati "Il vecchio con gli stivali", de 1949) los exjerarcas fascistas se purifican comprando inverosímiles certificaciones de antifascismo, y quienes pagan los platos rotos serían los humildes empleados de bajo nivel, los "vencidos" de siempre, depurados a pesar de no ser fascistas en absoluto. Y finalmente con Sciascia, quien expande aquella lectura de la historia al panorama nacional, a todo el "contexto" político-empresarial-mafioso como un entramado de corresponsabilidades y silenciosas complicidades, y al asociacionismo entre la mayoría, representada por la Democracia Cristiana, y la oposición, por el Partido Comunista, como en Il contesto (Sciascia, 1971), Todo modo (Sciascia, 1974), L'affaire Moro (Sciascia, 1978); sin mencionar al Sciascia del controversial artículo "I professionisti dell'antimafia" (Sciascia, 1987), ${ }^{4}$ donde las colusiones y los tránsitos entre mafia y antimafia son lo que sostiene aquel mismo teorema.

evangélica como un llamado a los hombres para que se amen recíprocamente 'como iguales y hermanos, llamados a hacer efectivas, con sabia reciprocidad de virtud y de labores, la magnífica suerte y progresiva de la humanidad"' (Leopardi, 1988: 178).

4 "Los profesionistas del antimafia", no traducido al español. 
Federico De Roberto, quien acuñó aquella clave de lectura, fue un lector voraz y un escrupuloso recensor no sólo de la literatura y de la cultura francesa de los siglos XVIII-XIX, de la cual era un especialista, sino también de las filosofías y las culturas "de la crisis", es decir las ideas, las formas y los nuevos saberes que - de Nietzsche a Bergson, de la psicología a la sociología, de Ibsen a Wagner-entre el siglo XIX y el XX transformaban en duda las certidumbres, las grandes síntesis, los fundamentos mismos del pensamiento tradicional, abriendo una larga y oscura transición de cuya fenomenología - marcada por la consternación y la alienación pero también por el triunfo del análisis y de la duda - el autor de I Vicerè fue un atento y curioso investigador, en revistas y diarios (en primer lugar el Corriere della Sera, del cual fue editorialista y columnista).

De estas corrientes de pensamiento se alimentaban su análisis escéptico y demistificador, y su crítica corrosiva, de las mentiras del poder y de los callejones sin salida del progreso: y por eso la antihistoria redactada entre muchos, y siempre del lado de los "vencidos" y de sus esperanzas derrotadas, por él y por los otros escritores sicilianos es todo menos que inmovilista y resignada (¿cuál gatopardismo? ¿cuál desconfianza en el progreso y coartada para la conservación?); y siempre en sintonía con las corrientes más vivas de la literatura europea, con los niveles más altos de la investigación crítica sobre "el hastío de la civilización" y de la experimentación de nuevos lenguajes capaces de expresarlo y descifrarlo.

En las columnas del Corriere della Sera será otro siciliano el que se alternará con De Roberto: Giuseppe Antonio Borgese, quien fue nada menos que el yerno de Thomas Mann. Gran germanista, crítico militante, quien firmó el manifiesto antifascista de Benedetto Croce y por eso fue exiliado en los Estados Unidos, donde escribió una ejemplar anti-historia de Italia, no por nada olvidada, Goliath, the March of Fascism (Borgese, 1937), Borgese fue un gran mediador de la cultura mitteleuropea. Después de la primera guerra mundial había publicado una novela, Rubè (Borgese, 1921) que es el más lúcido examen de consciencia de la intelectualidad italiana y un claro análisis de la alienación del siglo XX.

Pocas voces, como la suya y la de su discípulo ideal Brancati, a quien Borgese convenció que renegara su ingenuo fascismo juvenil, fueron portadoras de un sentido tan alto y riguroso - muy raro en Italia - de la responsabilidad individual, y de la misión ética que conlleva la profesión intelectual, el Beruf como fue teorizado por Max Weber, quien no por casualidad lo arraigaba en la ética protestante. Vitaliano Brancati encarnó esa ética con una feroz determinación, pagando en carne propia —en el momento de su conversión al antifascismo - el precio de la expiación y del comenzar de nuevo, de la radical reconversión de sus instrumentos intelectuales y expresivos, del exilio en el "tedio" de la provincia. Y fue quizá el único de los intelectuales italianos en vivir aquella traumática transición sin transformismos, con un sentido serio y exigente de la propia responsabilidad moral y profesional.

Mas en esos años él no era el único en considerar que la ausencia de la Reforma protestante en Italia - y por ende de una ética tan rigurosa además de la actitud 
crítica al "libre examen" - fuera la causa de muchos de nuestros males, de demasiadas indulgencias e incumplimientos; lo escribía Piero Gobetti en su Rivoluzione liberale y en Conscientia, la hermosa revista de fe protestante en la cual escribían entre otros, definiéndose "neo-protestantes", no pocos intelectuales sicilianos, como Titomanlio Manzella y Vito Mar Nicolosi, de Catania, y Luca Pignato y Calogero Bonavia, de Caltanissetta, este último maestro del joven Sciascia.

Éstos no son los únicos episodios que argumentan en favor de una inclinación mitteleuropea de los escritores de la isla: consideremos la convergencia de presencias —en aquellos años Veinte- en Berlín, y por ende en el mero corazón de tiniebla y asfalto de la Metropolis expresionista. Allí llegaba Luigi Pirandello, quien modelaba su Questa sera si recita a soggetto (Pirandello, 1930) sobre los protagonistas y las convenciones de la vanguardia teatral berlinesa; y allí llegaba también el otro gran dramaturgo, Pier Maria Rosso di San Secondo, un siciliano atípicamente "centrífugo": es decir, todo menos que arraigado al "escollo" al que se refiere Verga, y destinado a una fuga sin fin hacia el Norte de la geografía y del alma. En aquella Berlín suspendida entre expresionismo y "nueva objetividad", es decir entre el Grito inarticulado y primigenio del Hombre originario y el modesto vaniloquio del hombre cualquiera, Rosso escribía obras teatrales como La signora Falkenstein, Lo spirito della morte, Il segno verde (Rosso, 1976), ambientadas en los alrededores de la mítica Alexanderplatz, habitada por manadas de vagabundos, de parias, cuyas sordas violencias - $\tan$ afines a las de los personajes de Rossoescenificó, en aquel final de los años Veinte, Alfred Döblin en su novela titulada, precisamente, Berlin Alexanderplatz (Döblin, 1929).

En las mismas encrucijadas berlinesas pasaba el invierno el aún hoy desconocido Ruggero Vasari, un futurista de Messina que en Berlín, entre otras cosas, escribirá una vanguardista Angoscia delle macchine (Vasari, 1925), que inspirará la celebérrima obra maestra de Fritz Lang, Metropolis, prestando los trasfondos tecnológicos de la fábrica-Leviatán. Y no se puede concluir esta pequeña galería de sicilianos en fuga, que arribaron a latitudes - y experimentaciones - tan remotas y extremas (y por eso mismo castigados con el olvido) sin citar a Umberto Barbaro, novelista vanguardista y, sobre todo, máximo teórico del neorrealismo cinematográfico, en el cual volcará luces y sombras, angustias y furores del gran cine expresionista alemán.

Y se podría continuar esta larga historia de préstamos y fugas hasta llegar al descubrimiento de l'America por parte de Elio Vittorini, quien descubría y divulgaba Hemingway y Faulkner, el rigorismo calvinista de los pioneros puritanos y el mito vitalista y progresivo de la frontera, para refortalecer la consciencia europea, debilitada por los totalitarismos, para volver a comenzar la historia bajo la insignia de su mismo optimismo. De aquel optimismo, y específicamente del mito americano, el inventor, en los años del New Deal, había sido un oscuro migrante de la Sicilia pobre - Bisacquino, en provincia de Palermo - es decir, el gran director de cine Frank Capra. 
Finalmente, necesitamos volver a las predilecciones nuevamente orientadas hacia la Francia de Voltaire y de Stendhal (pero también, como ya vimos, hacia España) de Leonardo Sciascia. En Voltaire, en la aislada provincia de Enna, se había inspirado en los años Veinte y Treinta un refinado escritor como Nino Savarese; y a Stendhal, algunas décadas antes, se había referido el verista dandy Emanuele Navarro della Miraglia, quien, siendo originario del pueblo árabe Sambuca Zabút en el interior de la provincia de Agrigento, se formaría en la París decadente y simbolista.

Una larga historia, como hemos visto. Sin embargo, es importante observar que la xenofilia y la abertura al mundo de nuestros escritores se conjugan con la tensión, al contrario, centrípeta, que domina sus obras, obsesivamente ligadas al tema de la isla, y sus vidas crucificadas a aquella tierra amada y odiada, o cuando menos condenadas a concluirse allí, en desolados regresos que a veces tienen el mismo sentido de derrota abrazadora y rencorosa desconfianza que el arraigo de las "ostras" de Verga al "escollo". A un orgulloso silencio, que duró veinte años, se condenó el gran Verga, cuyo desdén hacia la nueva Italia y su literatura palabrera y amateur se materializó en el rechazo de la escritura, en los ociosos rituales de la provincia, en una mezquina sobrevivencia de viejo y desdeñoso terrateniente.

Él sí volvía al escollo del cual no habría querido que sus "vencidos" se desarraigaran; pero volvía derrotado, tal y como, más tarde, Federico De Roberto y después el joven y genial escritor Francesco Lanza, autor de los feroces Mimi siciliani (1928), ${ }^{5}$ a quien, cuando estaba listo para salir volando a las capitales de la cultura lo tomó por sorpresa, a medio camino, un problema de salud que lo regresó moribundo a la odiada "trampa" (así la había definido) de Valguarnera, su pueblo nativo. Regazo acogedor y trampa mortal, la isla: Edén prenatal en el cual refugiarse y cárcel de perezosos hábitos y desgastados prejuicios, observatorio privilegiado para juzgar y desenmascarar la historia y tumba de rencores y presagios desesperados. Quizá, como los personajes de Brancati, emigrados en la capital y temporalmente convertidos a hábitos más dinámicos, que regresan allá por uno o dos días, listos para volver a irse, acabando por quedar enredados en una tibieza gratificadora, en un torpor sin responsabilidades, vigilado por madres y hermanas ansiosas y posesivas.

O quedan cautivados por el laberinto de calles y plazas demasiado familiares, pero que desorientan como una serie de salones del castillo de Atlante, donde una muchedumbre de hombres se entrecruza, muda, cada uno en su búsqueda secreta, itinerarios sinuosos se entrelazan y se persiguen espejismos vanos, dando de espaldas en cada cruce contra oscuros compañeros de pena de los cuales ni siquiera se percatan, y menos de los fantasmas que ellos también persiguen ciegamente. La Catania de Brancati, como la de De Roberto y - se podría decir- como la topografía centrípeta y reclusoria de los escritores sicilianos, es un espacio cerrado

${ }^{5}$ Mimos sicilianos, no traducido al español. 
como un interior, un estrecho laberinto de existencias segregadas, y nada tiene que ver con el mapa urbano real, al estar drásticamente limitado a pocos espacios (los interiores de De Roberto, nidos de víboras y galerías de monstruos; las calles de Brancati, cubiertas y encerradas por el "cielo de la provincia, bajo e íntimo como un cielorraso"), y reducida a un espacio simbólico de dolorosa expiación o de sueño impotente. Allí se puede pasar una vida entera amando sin esperanza a una mujer a quien nunca se encontró, o soñando levantar allí una torre que arranque el alma de la monotonía del "tiempo perdido"; o regodeándose en una metafísica impotencia que, sin embargo — como la del Bell'Antonio (Brancati: 1949a)—, se eleva a la dignidad de una noble protesta ante los ciegos activismos, el bruto fanatismo de las dictaduras.

Una vez más la doble referencia a la trágica historia del Novecento europeo y a la gran literatura que denunció sus horrores se manifiesta justo cuando parecerían prevalecer el repliegue y la cerrazón. Marginalidad geográfica y soledad existencial, entonces, como una consecuencia de una febril curiosidad para las latitudes y culturas más remotas; de esta paradoja se nutre la anti-historia, pesimista y escéptica, formulada por nuestros escritores desde lo alto de su remoto observatorio, desde el cual todo evento y toda idea parece una impostura por desmitificar, una transformista perpetuación del Poder.

La última figura emblemática de este exilio poblado de libros y voces fue la de Gesualdo Bufalino, inmóvil en su natal y remota Comiso, diariamente ocupado en los rituales provincianos del paseo en la avenida principal o del juego de naipes en el Círculo, mientras que en sus noches insomnes lo visitaban por encanto Baudelaire y Proust, Cervantes y Tolstoi, los personajes de novela de cien países y tradiciones literarias. Una de las "cien Sicilias", la de Bufalino (Cento Sicilie es un título suyo [Bufalino y Zago: 1993]): una de las muchas Sicilias, quizá la última. Y seguramente "la última provincia" (si se vale robar otro título, esta vez de Luisa Adorno [1983]) fue aquella provincia de Ragusa, aquella provincia apodada babba, una provincia "sosa" (es decir hasta hace poco civil, hasta hace poco incontaminada por la homologación de la Mafia), que representó el finis Siciliae no sólo como extremo límite geográfico sino también como última encarnación histórica de una utopía: la utopía de una identidad intacta, orgullosamente antagonista como la de los campesinos de Serafino Amabile Guastella, viva a pesar de los anatemas nacionalistas de Giovanni Gentile, el lúgubre profeta del "ocaso de la cultura siciliana".

Existe además (o existía) la Sicilia de tradición burguesa y democrática, cuya capital es Catania, patria del verismo de Verga y De Roberto, y de la comicidad de Angelo Musco y Vitaliano Brancati; existe (o existía) la Palermo aristocrática de los "gatopardos", del abad Meli y el príncipe Tomasi di Lampedusa; existe (o existía) la vasta provincia de Messina propensa al experimentalismo lingüístico, la de los futuristas como Beniamino Joppolo, la de Lucio Piccolo, Stefano D'Arrigo y Vincenzo Consolo; existe (o existía) el centro soleado y desolado de las minas y del latifundio de Alessio Di Giovanni y Rosso di San Secondo, de Francesco Lanza 
y Nino Savarese; y finalmente existe (o existía) la Sicilia árabe, escéptica y amarga, de la mafia y de la muerte, de la angustia civil y existencial, de los trágicos sofismos de Pirandello (pero también de Giovanni Gentile), de las laicas inquisiciones de Leonardo Sciascia, pero también de las novelas seudohistóricas y de la afortunada serie policíaca de Andrea Camilleri, impregnadas del amargo "humorismo" pirandelliano y de la aguda ironía de Brancati.

¿Y las mujeres? Es una pregunta legítima: porque este escrito, como las historias actuales de las letras patrias, corre el riesgo de borrar existencias apartadas y operosas, como las de las poetisas del siglo XIX Mariannina Coffa y Giuseppina Turrisi Colonna, u otras que sólo ahora están siendo sustraídas al olvido, por mucho tiempo pisoteadas por un persistente código patriarcal en Sicilia, una región donde por otro lado un feliz, enérgico, libertario matriarcado sobrevivió por siglos, testimoniado en la literatura más conocida casi únicamente por las mujeres y madres orgullosas y emancipadas de Elio Vittorini. Entre estas últimas baste aquí recuperar, entre el bullicio del comienzo del siglo Xx, los silencios, el expresivo pudor y los vértigos provincianos de una pequeña Virginia Woolf isleña como Maria Messina, nativa de la sierra de las Madonie, apreciada por Borgese y digna de figurar a la par de Federigo Tozzi por sus llamados a un "tiempo de edificar" nuevas formas narrativas. Y, por el contrario, en la literatura posbélica entre neorrealismo y nuevas experimentaciones, la personalidad detonante de Goliarda Sapienza, de Catania, autora de novelas que oscilan de manera genial entre memoria y revuelta, como el denso L'arte della gioia (Sapienza, 1998) y el encantador Io, Jean Gabin (Sapienza, 2010), por no hablar finalmente de un florecimiento de escritoras sicilianas quienes, desde los años Ochenta del siglo pasado hasta nuestros días superan la abundante producción masculina.

Un continente, entonces, Sicilia; y un teatro de la memoria, en el cual se alternaron y sobrepusieron etnias y culturas, códigos y lenguajes: algunos presentes y vivos, y evocados por sus escritores, otros subterráneos, o más bien removidos. Éste es el caso de la fundamental huella árabe, es decir de una civilización que, incluso si fue considerada — por Michele Amari y Leonardo Sciascia- quizá el punto más alto de la historia de Sicilia, ha sido olvidada, ocultada: por ejemplo, la de los poetas árabes de Sicilia, quienes desde el exilio cantaron la asoladora añoranza de la isla, que sentían como patria, nido de afectos familiares, espacio de civilización. Sólo hoy, quizá, asistimos a un fuerte fenómeno de recuperación de aquellas raíces, de resarcimiento de aquella herida: y no tanto en el nivel literario sino más bien en la música, con autores como Franco Battiato e inclusive fenómenos más recientes de música étnica y rock, que recuerdan sonoridades del Maghreb $\mathrm{o}$ árabo-andaluzas, y se nutren de metáforas y conceptos tomados de la sapiencia de los sufi del Islam.

Una herida remota, y por eso duradera. Pensemos en los versos de Ibn Ḥamdîs, poeta árabe de Noto, sobre la isla perdida para siempre: "llenos los ojos, y vacías las manos, del recuerdo de ella..." (Sciascia, 1970: 10). Árabe y siciliano, el poeta 
exiliado, desterrado de su patria-Sicilia, canta la devastadora añoranza para aquella tierra que era suya, con el mismo tormento con el cual sus descendientes y correligionarios de hoy añoran, en tierra de Sicilia, su patria africana o del Oriente medio. Llenos los ojos: del recuerdo, apasionado y doloroso, inalienable. Y vacías las manos: de la posesión, perdida por siempre. Y ¿qué otra cosa es, hasta el día de hoy, esta isla para los escritores que la cantaron, y, en parte, la reinventaron? Una añoranza, un espejismo, una utopía en su acepción etimológica de lugar que no existe, o que ya no existe más, a partir de una originaria diversidad antropológica que ya ha sido arrasada por la modernización y por la homologación, pero que puede ser aún evocada por sus escritores, "llenos los ojos, vacías las manos, del recuerdo de ella", y que se vuelve a presentar en forma de desconfianza intelectual y superioridad moral, de laboratorio de inteligencia crítica y desmitificadora.

La de la insularidad es, al fin y al cabo, una paradoja: condición que en otro lugar permitió una abertura centrífuga, un medio para la expansión y la conquista, la fuga y la aventura (pensemos en otra literatura insular, la británica de Swift, De Foe, Stevenson y Conrad) y al contrario - para los escritores sicilianos- baluarte de cerrazón desconfiada y de defensa: de una mar de la cual casi nunca hablan, sino como la "mar amarga" de Verga que trae desdicha y, como un tiempo trajo incursiones e invasiones, hoy trae un progreso mendaz y alienante; de una mar a la cual no le queda otra cosa que resistir, arraigándose al "escollo", volteándole la espalda y mirando más bien hacia un "centro" perdido, una tierra desconsagrada. Y esto no obstante de aquella casa, de aquel escollo, ya en los años de los Malavoglia (1881) los primeros grandes flujos migratorios estaban desarraigando a esos "vencidos". Y esto a pesar de que, en unos años, el siciliano Giovanni Gentile, en el Il tramonto della cultura siciliana $(1919)^{6}$ reprochara esta vocación al aislamiento, los presuntos retrasos culturales (aunque sería más preciso decir: la coherente vocación crítica) de la isla "secuestrada"...

Una paradoja, entonces; la última de una serie de felices, y fecundas, paradojas: a las cuales les debemos la inactual modernidad de la literatura siciliana. Y de cómo este aislamiento, esta marginalidad geográfica, esta desconfianza intelectual puedan colocarse, en virtud de una paradójica acrobacia, a la vanguardia, lo comprueba la incesante innovación lingüística de los sicilianos, que en el tronco del dialecto injertan atrevidísimas experimentaciones, como el vertiginoso discurso indirecto libre de Verga, con el que las nervaduras sintácticas, los exabruptos coloquiales, las rápidas condensaciones del dialecto irrumpen en la lengua literaria, descuadernándola y refundándola, y en un crescendo hasta la verdadera neolengua, joycianamente reinventada por D'Arrigo, en su obra maestra Horcynus Orca (1975).$^{7}$

${ }^{6}$ El ocaso de la cultura siciliana, no traducido al español.

${ }^{7}$ Novela publicada después de una elaboración de más de veinte años (dos capítulos de una primera versión fueron publicados en la revista Il Menabò en 1960), representa un unicum en la literatura italiana. 
Suntuoso y visionario, barroco e hiperbólico, desgarrador y feroz, el gran libro de las fere y de los pellisquadre, de las femminote y del orcaferone $^{8}$ es una epopeya degradada y carnavalesca, y sin embargo milagrosamente polifónica y totalizadora. Y el regreso del antihéroe Ndrja Cambrìa en los lugares natales de Scilla y Cariddi a través de los infiernos de la guerra y de la miseria se configura como una iniciación a la muerte y al mismo tiempo un irrepetible viaje en la escritura, lozana oficina de mitos e invenciones lingüísticas.

Si el "mundo de ayer" desapareció, o está a punto de desaparecer, es preciso entonces inventarlo, rescatarlo como una atrevida utopía, y transformarlo en una lengua que renombre - y refunde - la realidad. Tal y como en el Angelus Novus de Paul Klee, del cual habla Walter Benjamin, la literatura de los sicilianos voltea la mirada hacia el pasado y a sus ruinas, mientras que el frémito de sus alas la impulsa irresistiblemente hacia adelante, hacia el futuro. No es casual, por otro lado, que la vanguardia futurista, la única que le tocó en suerte a una literatura tan cautelosa y bien educada como la italiana, haya escenificado una buena parte de sus intemperancias en tierra de Sicilia, donde no hay un pueblo que no abundara en revistas y performances de palabras en libertad; ni, después, que estos descarados vanguardistas homenajearan el genio deseñoso de Verga o mendigaran el condescendiente patrocinio del verista Capuana.

Y es del sólido tronco de Verga que brotan las dos ramas de la literatura siciliana contemporánea: del Verga épico-lírico de Vita nei campi (Verga: 1897) y de los Malavoglia (Verga: 1881) aún con la ilusión de salvar el puerto franco de sus casas del níspero y granjas del pino del acecho a la redonda de la modernización alienante y homologante, se propaga la línea evocativa y mitificante de los Elio Vittorini, Stefano D’Arrigo, Giuseppe Bonaviri, Vincenzo Consolo; de la amarga desilusión y del "universo horrendo", e irreversiblemente cosificado, de las Rusticane (Verga: 1883) y de Mastro don Gesualdo (Verga: 1889) y del definitivo

Relata en más de mil páginas el mítico regreso a casa, durante la desbandada del ejército italiano que sigue al armisticio con los Aliados el 8 de septiembre de 1943, del marinero 'Ndrja Cambrìa. La narración cubre — con un notable recurso a flashbacks, digresiones y flujo de conciencia - un arco de cinco días, del 4 al 8 de octubre de 1943, durante los cuales el protagonista logra cruzar el Estrecho de Mesina, a pesar de que la navegación haya sido interrumpida por la guerra, y regresar a su tierra. Con un lenguaje híbrido que mezcla italiano literario, dialecto siciliano y neologismos acuñados por el autor y referencias —-temáticas y estilísticas - a la Odisea y al Ulysses joyciano, pero también a Moby Dick y a la obra de Verga. Ha sido traducida únicamente al alemán, por Moshe Kahn (D’Arrigo: 2015).

${ }^{8}$ En la mitografía creativa de D'Arrigo, la fera es el delfín, odiado por los pescadores porque desgarra sus redes y cuya carne es considerada inmunda, pero también protagonista de una serie de recuerdos de infancia del protagonista; los pellisquadre son metafóricamente los pescadores, ya que el término se refiere literalmente al tiburón, por su piel áspera; las femminote son mujeres de Calabria que tienen su propio pueblo a la orilla del mar y comen fere: una de ella, Ciccina Circè, con la ayuda de las fere que ella hechiza tocando un cascabel, es la que trasborda a 'Ndrja, a cambio de sus favores sexuales; el orcaferone es un Orca que periódicamente despierta y asesina a los pescadores, quienes la consideran como un delfín especial, la fera mayor: en una narración mítica se establece una genealogía femenina que comienza con las sirenas y sigue con las fere - y, por lo tanto, con el orcaferone - y con las femminote. 
silencio, última inefable creación en la cual se encarna la orgullosa protesta de Verga), se deriva la línea analítica y crítica, problemática y plurilingüista, que - con la aportación de las contribuciones raciocinantes de De Roberto y sofísticas de Pirandello-, sigue con Borgese, con Brancati, con Sciascia, o con escritores ásperos e inaccesibles como Angelo Fiore o Antonio Pizzuto.

Dos líneas, claro está, variamente entrelazadas. Y una única, ininterrumpida elaboración intelectual y estilística, como una estafeta, un cambio de testigo de un autor al siguiente, quien hereda sus juicios, metáforas y recursos estilísticos. Una apuesta colectiva, un reto: seguramente una desmentida apabullante a las engreídas profecías del idealista - y nacionalista - Giovanni Gentile, molesto por aquel rigor de marca positivista, y más molesto aún por aquella implacable contestación. Por supuesto, lo que el filósofo, siciliano de Castelvetrano, deseaba, era integrar - y así redimensionar - en el seno de la cultura nacional, hegemonizada por el idealismo, la irreducible diversidad de la literatura siciliana, de su tradición materialista y realista y su orgullosa alteridad, su prejuicio crítico sobre la magnífica suerte de la Nación proclamada por el Poder, su vocación a la duda $\mathrm{y}$ al disentimiento.

Pues bien: son justamente estos rasgos, invariados, los que permitieron, mucho más allá del ultimátum de Gentile, y justo hasta Sciascia, hablar de Sicilia y de literatura siciliana como de la última cultura regional que sobrevivió a la homologación: precisamente gracias a sus escritores, a su tenaz y desesperado aferrarse a temas y lugares y lenguajes autóctonos, y aún más a esas raíces culturales, a ese mito de clausura desconfiada y de terca autodefensa, a esa lección de añoranza desencantada y de dudosa desmitificación. Empero se trata de un repliegue que, como se ha observado, los proyectaba en el corazón y en el tormento de la conciencia europea; una marginación que, saltándose las capitales itálicas del efímero éxito y consenso del régimen, los conectaba directamente, desde su remota posición, con las grandes capitales del alma.

Mientras tanto, la realidad efectiva, la isla real se habían homologado por su cuenta; más bien, ellas mismas contribuían tristemente a esa homologación, a la par que la "palmera" mafiosa (la imagen es de Sciascia) subía hacia "el Norte". Y sólo la literatura siguió resistiendo en esa trinchera de desertores, transformando (éstas también son palabras de Sciascia) una "ausencia" en "esencia", es decir la efectiva desaparición de aquella Sicilia-ostra incontaminada - y orgullosamente "secuestrada" - en una estrategia de moralidad y estilo, en una trinchera de la inteligencia crítica: "vacías las manos, y llenos los ojos en el recuerdo de ella". Por ende, defendiéndonos de los venenos del day after al inventarnos una memoria.

A futura memoria se tituló la última recopilación póstuma autorizada por Sciascia (1989): quien, sin embargo, siendo un profeta desencantado, la subtituló así: (se la memoria ha un futuro). ${ }^{9}$ Sabía que era él la última garantía de aquel

\footnotetext{
${ }^{9}$ Para futura memoria (si la memoria tiene futuro), no traducido al español.
} 
futuro: él, quien había mantenido vivos los sentidos y las ideas de la sicilitudine ${ }^{10}$ justo para censarlos, antes del fin; él, quien aprendió a indignarse y a esperar en el fuego de la guerra de España y en la Francia de la utopía ilustrada, aprendió de la gran narrativa del XIX y XX a cultivar la utopía de una literatura que imponga un orden nuevo y más justo, una "sintaxis" al "mundo ofendido. No obstante, a este mundo ofendido Sciascia se volvió a entregar en su lecho de muerte: a esto, desde el comienzo, estaba condenado, por ese recato isleño, ese pudor desconfiado, esa tenaz aunque no expresada esperanza, de la cual habla el personaje Ippolito Nievo en "Il Quarantotto" (Sciascia: 1958) con respecto a un garibaldino siciliano, pero parece referirse al autor, al callado, melancólico, inflexible maestro de Regalpetra: ${ }^{11}$

\begin{abstract}
Porque - dijo Nievo - yo creo en los sicilianos que hablan poco, en los sicilianos que no se agitan, en los sicilianos que se roen por dentro y sufren: los pobres que nos saludan con un gesto cansado, como desde una lejanía de siglos; y el coronel Carini siempre tan callado y lejano, amasado con melancolía y tedio pero en cada momento listo para la acción: un hombre que parece no tener muchas esperanzas y sin embargo es el corazón mismo de la esperanza, la callada, frágil esperanza de los sicilianos mejores...una esperanza, diría yo, que se teme a sí misma, que le tiene miedo a las palabras y al contrario tiene cercana y familiar a la muerte...
\end{abstract}

La "callada, frágil esperanza" de Leonardo Sciascia y del juez Giovanni Falcone, asesinado por la mafia; la misma fe vulnerable y tenaz de la cual nos alimentamos diariamente "esperando en contra de la esperanza", indignándonos y empecinándonos, y que intentamos — como podemos y sabemos - transmitir a nuestros discípulos, a quienes nos leen o nos escuchan, "para futura memoria".

\title{
Referencias bibliográficas
}

Adorno, Luisa. (1983). L'ultima provincia. Palermo: Sellerio.

BORGESE, Giuseppe Antonio. (1921). Rubè. Milán: Mondadori.

Borgese, Giuseppe Antonio. (1937). Goliath, the March of Fascism. Nueva York: The Viking Press.

Borgese, Giuseppe Antonio. (1946). Golia: marcia del fascismo (Doletta Caprin Oxilia, Trad.). Milán: Mondadori.

BrancATI, Vitaliano. (1949a). Il bell'Antonio. Milán: Bompiani.

${ }^{10}$ Neologismo acuñado por Sciascia ("sicilitud") en alternativa a sicilianità, traducible como "sicilianidad".

${ }^{11}$ Sciascia nació en Racalmuto, en provincia de Agrigento; publicó en 1956 el libro Le parrocchie di Regalpetra, pueblo de Sicilia que no existe, cuyo nombre es una fusión entre Racalmuto y el título del libro de Nino Savarese (1937) I fatti di Petra. Storia di una città. (Los acontecimientos de Petra, historia de una ciudad, no traducido al español). 
BRANCATI, Vitaliano. (1949b). "Il vecchio con gli stivali". Il vecchio con gli stivali e altri racconti. Milán: Bompiani. 113-146.

Brancati, Vitaliano. (1985). El viejo con Botas (Guillermo Fernández, Trad.). México: UNAM (Material de Lectura, 26).

Brancati, Vitaliano. (2009). "El Bello Antonio". Tríptico Siciliano (Ángel Sánchez-Gijón y Rosa, Trad.). Barcelona: Lumen.

Bufalino, Gesualdo; y Zago, Nunzio. (1993). Cento Sicilie. Testimonianze per un ritratto. Scandicci: La Nuova Italia.

D’Arrigo, Stefano. (1975). Horcynus Orca. Milán: Mondadori.

D’Arrigo, Stefano. (2015). Horcynus Orca (Moshe Kahn, Trad.). Frankfurt: S. Fischer Verlag.

DE RoBERTO, Federico. (1894). I Vicerè. Milán: Galli.

De Roberto, Federico. (1929). L'Imperio. Milán: Mondadori.

De Roberto, Federico. (2008). Los Virreyes (José Ramón Monreal Salvador, Trad.). Barcelona: Acantilado.

De Roberto, Federico. (2014). El Imperio (Mónica García Aguilar, Trad.). Granada: Traspiés.

Di GrAdo, Antonio. (2009). "Memoria e utopia: la vocazione europea della letteratura siciliana”. Fragmentos. Revista de Língua e Literatura Estrangeiras da Universidade Federal de Santa Catarina. Literatura italiana do século XX, (36), 13-25. https://doi.org/10.5007/fragmentos.v0i36.24180

DöBlin, Alfred. (1929). Berlin Alexanderplatz. Berlín: S. Fischer Verlag.

DöBlin, Alfred. (2002). Berlín Alexanderplatz (Miguel Sáenz, Trad.). Madrid: Cátedra.

GENTILE, Giovanni. (1919). Il tramonto della cultura siciliana. Bologna: Zanichelli. HamDîs, Ibn. (1998). Il Canzoniere nella traduzione di Celestino Schiaparelli.

Palermo: Sellerio.

LANZA, Francesco. (1928). Mimi siciliani. Milán: Alpes.

LeOPARDI, Giacomo. (1835). "La Ginestra”. Canti. Napoli: Starita.

LEOPARDI, Giacomo. (1988). Canti. Milán: Rizzoli.

LEOPARDI, Giacomo. (2002). Cantos (Juan Bautista Bertrán, Trad.). Barcelona: Ediciones 29.

PIRANDello, Luigi. (1913). I vecchi e i giovani. Milán: Treves.

PIRANDELlo, Luigi. (1930). Questa sera si recita a soggetto. Milán: Mondadori.

PirAndello, Luigi. (1992). Esta noche se improvisa (Miguel Ángel Cuevas, Trad.). Madrid: Cátedra.

Pirandello, Luigi. (2012). Viejos y jóvenes (María Teresa Navarro Salazar, Trad.). Barcelona: RBA.

Rosso Di SAN SECONDO, Piermaria. (1976). Tutto il teatro. Roma: Bulzoni. SAPIENZA, Goliarda. (1998). L'arte della gioia. Roma: Stampa Alternativa.

SAPIENZA, Goliarda. (2007). El arte del placer (José Ramón Monreal Salvador, Trad.). Barcelona: Lumen. 
SAPIENZA, Goliarda. (2010). Io, Jean Gabin. Torino: Einaudi.

SAPIENZA, Goliarda. (2017). Moi, Jean Gabin (Nathalie Castagné, Trad.). París:

Le Tripode.

Savarese, Nino. (1937). I fatti di Petra. Storia di una città. Milán: Mondadori.

SCIASCIA, Leonardo. (1956). Le parrocchie di Regalpetra. Torino: Einaudi.

SCIASCIA, Leonardo. (1958). "Il Quarantotto". Gli zii di Sicilia. Torino: Einaudi. 85-147.

SCIASCIA, Leonardo. (1960). "L'antimonio". Gli zii di Sicilia. Torino: Einaudi. 151-199.

SciAscia, Leonardo. (1970). "Sicilia e Sicilitudine". La corda pazza. Torino: Einaudi. 3-10.

ScIASCIA, Leonardo. (1971). Il contesto. Una parodia. Torino: Einaudi.

SCIASCIA, Leonardo. (1974). Todo modo. Torino: Einaudi.

SCIASCIA, Leonardo. (1978). L'affaire Moro. Torino: Einaudi.

ScIASCIA, Leonardo. (1981). El contexto (Carmen Artal Rodríguez, Trad.). Barcelona: Bruguera.

Sciascia, Leonardo. (1982). Todo modo (Joaquín Jordá, Trad.). Barcelona: Bruguera.

SCIASCIA, Leonardo. (1983). Las parroquias de Regalpetra (Rossend Arqués, Trad.). Barcelona: Bruguera.

SCIASCIA, Leonardo. (1987, 10 de enero). "I professionisti dell'Antimafia”. Corriere della Sera. 3.

SCIASCIA, Leonardo. (1989). A futura memoria (se la memoria ha un futuro). Milán: Bompiani.

ScIASCIA, Leonardo. (2001a). "El antimonio". Los tíos de Sicilia (Alfredo Citraro, Trad.). Barcelona: Tusquets. 180-250.

SciAsciA, Leonardo. (2001b). "El Cuarenta y ocho". Los tíos de Sicilia (Alfredo Citraro, Trad.). Barcelona: Tusquets. 105-178.

Sciascia, Leonardo. (2011). El caso Aldo Moro (Juan Manuel Salmerón, Trad.). Barcelona: Tusquets.

ScIAscia, Leonardo. (2012). Opere. Vol. I, II, III. Milán: Adelphi.

TEMPIO, Domenico. (1848). La Caristia. Catania: Vincenzo Percolla.

Tomasi di Lampedusa, Giuseppe. (1958). Il Gattopardo. Milán, Feltrinelli.

Tomasi Di LAmPedusA, Giuseppe. (2019). El Gatopardo (Ricardo Pochtar, Trad.). Barcelona: Anagrama.

VASARI, Ruggero. (1925). L'angoscia delle macchine. Torino: Edizioni Rinascimento.

Verga, Giovanni. (1881). I Malavoglia. Milán: Treves.

Verga, Giovanni. (1883). "Libertà”. Novelle rusticane. Milán: Treves. 241-247.

VERGA, Giovanni. (1889). Mastro don Gesualdo. Milán: Treves.

Verga, Giovanni. (1897). Vita dei campi. Milán: Treves. 
Verga, Giovanni. (1998). Los Malavoglia (Cipriano Rivas Cherif, Trad.). Madrid: Espasa-Calpe.

Verga, Giovanni. (2003). Maestro-don Gesualdo (José H. Amieva, Trad.). La Habana: Arte y Literatura.

Verga, Giovanni. (2014). La vida en los campos (Hugo Bachelli, Trad.). Madrid: Periférica.

Verga, Giovanni. (2019). “Libertad”. Estampas Sicilianas (Guillermo Fernández Trad.). Toluca: Secretaría de Educación del Estado de México, La canción de la Tierra. 211-226. 